\title{
The impact of COVID-19 on the male genital tract: A qualitative literature review of sexual transmission and fertility implications
}

\author{
Pierangelo Verrienti, Gianmartin Cito, Fabrizio Di Maida, Riccardo Tellini, Andrea Cocci, Andrea Minervini, Alessandro Natali \\ Department of Urology, Careggi Hospital, University of Florence, Florence, Italy
}

The angiotensin-converting enzyme 2 receptor (ACE2) appears to be widely expressed in cells in the testes, predominantly in spermatogonia, Sertoli cells, and Leydig cells, and its co-expression with transmembrane protease serine 2 (TMPRSS2) is essential for the entry of severe acute respiratory syndrome coronavirus 2 (SARS-CoV-2). For this reason, the male reproductive system could be considered a potential target for SARS-CoV-2, as well as a possible reservoir of infection. However, to date, there is very little evidence about the presence of SARS-CoV-2 in semen and testicular samples. The aim of this paper was to review the current evidence regarding the impact of SARS-CoV-2 on male fertility and sexual health, with a particular focus on reproductive hormones, the presence of the virus in seminal fluid and testis, and its impact on fertility parameters. We found very limited evidence reporting the presence of SARS-CoV-2 in semen and testicular samples, and the impact of SARS-CoV-2 on reproductive hormones and fertility parameters is unclear. The quality of the examined studies was poor due to the small sample size and several selection biases, precluding definitive conclusions. Hence, future well-designed prospective studies are needed to assess the real impact of SARS-CoV-2 on male reproductive function.

Keywords: COVID-19; Fertility; Male; Pathology; Physiology; SARS-CoV-2; Semen analysis; Testis

\section{Introduction}

The male genital tract is a target organ for several viral infections, with potential detrimental consequences from the standpoint of individuals, their offspring, and demographics [1]. A new type of coronavirus (severe acute respiratory syndrome coronavirus [SARS-CoV-2] [2]), has rapidly spread among humans, causing a worldwide pandemic. This virus causes a disease known as coronavirus disease 2019 (COVID-19), which is characterized by acute bilateral interstitial pneumonia and severe acute respiratory syndrome, which may lead to death in a short time [2].

Received: March 23, 2021 · Revised: November 22, 2021 · Accepted: December 27, 2021 Corresponding author: Pierangelo Verrienti

Department of Urology, Careggi Hospital, University of Florence, Largo Brambilla, 350134 Florence, Italy

Tel:+39-0557949203 E-mail: pierangelo.verrienti@gmail.com

This is an Open Access article distributed under the terms of the Creative Commons Attribution Non-Commercial License (http://creativecommons.org/licenses/by-nc/4.0/) which permits unrestricted non-commercial use, distribution, and reproduction in any medium, provided the original work is properly cited.
In order to contain the spread of this infection and to properly inform the public about appropriate safety measures, it is pivotal to identify all the possible pathways of viral transmission. Besides the typical well-known respiratory route of transmission through droplets, the oral-fecal route due to gastrointestinal viral involvement should also be considered. Moreover, sexual transmission and the immune privilege of the male reproductive tract may play a significant role in the spread of an infectious disease.

Some prior studies explored the potential sexual and vertical transmission of previous epidemic coronaviruses, focusing on possible viral effects on fetuses and newborns in infected women [3,4]. Therefore, it is crucial to provide proper counseling for couples with regard to their sexual behaviors, particularly in asymptomatic or recovered individuals.

Based on our knowledge of other single-stranded RNA viruses, such as Zika and Ebola, which have also been responsible for recent widespread epidemic viral infections $[5,6]$, it could be hypothesized - despite the clear differences between SARS-CoV-2 and the above-mentioned viruses-that the male genitalia could represent 
a possible reservoir for SARS-CoV-2, leading to its sexual transmission by asymptomatic or cured men [7]. Indeed, Zika and Ebola viruses are able to cause viremia, overcome the blood-testis barrier, and ultimately become present in semen [5-7]. The presence of Zika virus in human semen has been widely demonstrated for over 188 days after primary infection, even though it is cleared in the serum after the initial viral symptoms subside [8]. As a result, an immune response might be activated, leading to inflammatory processes such as orchitis, resembling what happens in human immunodeficiency virus (HIV), hepatitis B virus (HBV), and mumps infection [9]. However, extensive information about its potential impact on male fertility is currently lacking. Ebola can also persist in bodily fluids during recovery, enabling viral transmission through semen [6]. Preliminary results have shown that male survivors of Ebola virus disease can have virus-positive semen for up to 9 months after the acute infection, as determined by reverse-transcription polymerase chain reaction (RT$P C R)$ [6]. However, it is unknown with absolute certainty how long the virus can persist in the seminal fluid. Likewise, there are no conclusive data about the medium- or long-term consequences of Ebola virus on male fertility.

In this light, several case series have assessed the possible role of SARS-CoV-2 in male fertility impairment, with inconsistent results; the findings are also difficult to interpret because transmission through droplets can clearly occur during intimate sexual contact $[7,10,11]$. As such, in the current paper, we attempted to thoroughly explore the impact of SARS-CoV-2 on male fertility and sexual health by conducting a non-systematic review of the literature.

\section{Search strategy}

Medline, Embase, and Scopus Library were searched to identify studies published between January 2020 and March 2021 that investigated the impact of SARS-CoV-2 on male fertility. We conducted a non-systematic critical assessment of the current literature focusing on the impact of SARS-CoV-2 on reproductive hormones and fertility parameters, as well as its presence in seminal fluid and the testis. The following string terms were used: ("COVID-19" OR "SARS-CoV-2") AND ("reproductive hormones" OR "fertility" OR "semen" OR "testis"). We report a detailed description of the findings extracted from the included studies.

\section{Pathophysiology and the molecular mechanism of COVID-19 cell entry}

The entrance of SARS-CoV-2 into target host cells has been shown to be mediated by the interaction between the surface spike viral protein (S) and the angiotensin-converting enzyme 2 receptor (ACE2), employing the cellular transmembrane protease serine 2 (TMPRSS2). Therefore, the co-expression of these is needed within the same cell to allow viral entry $[12,13]$. As a protease, TMPRSS2 is essential for SARS-CoV-2 to penetrate cells, but many cells in the male genital tract do not express these proteins simultaneously with ACE2 [13-15]. However, other authors demonstrated that there was almost no overlapping gene co-expression $(<1 \%)$ in the human testicle [12]. The S1 site contains a receptor-binding domain, which then links to ACE2 and facilitates viral entry into the cell. ACE2 is expressed in various organs, including type II alveolar cells of lungs, heart, kidneys, and intestines [16]. In addition, ACE2 seems to be constitutively expressed in the testes, predominantly in spermatogonia, Sertoli cells and Leydig cells $[17,18]$. Most recently, Vishvkarma and Rajender [19] found the presence of ACE2 transcripts in recent transcriptome sequencing of human spermatozoa, further validating its expression in germ cells. The physiological functions of ACE2 in Leydig cells include the regulation of testosterone production and local balance in interstitial fluid volume by modulating the conversion of angiotensin II to angiotensin I. In the COVID-19 infection process, ACE2 receptors are saturated by binding with the virus, giving rise to the increased availability of angiotensin II, which cannot be converted.

As confirmed by recent studies, the levels of ACE2 transcripts are extremely high in the normal adult testes [13]. Spermatogonia that express ACE2 have higher levels of genes associated with viral reproduction and transmission, but lower levels of genes related to spermatogenesis, than ACE2-negative spermatogonia [20]. This has generated the idea that COVID-19 could have possible implications for the male genital tract, which could be considered a potential target for SARS-CoV-2, as well as a possible reservoir of infection. In this regard, it might be hypothesized that the virus could have a negative influence on male gonads, resulting in spermatogenetic injury and endocrine dysregulation.

In 2006, Xu et al. [11] demonstrated a wide range of histological injuries to germ cells and spermatogenesis, through a complex inflammatory infiltrate, in males who died from SARS-CoV complications, implying a correlation between the disease and subsequent reproductive impairment. SARS-CoV, as well as HIV, HBV, and mumps, can trigger orchitis as a possible complication due to body temperature increase and the virus-induced autoimmune response [9]. Indeed, previous studies, have reported that apoptosis of meiotic germ cells occurs at high temperatures [21]. Therefore, high fevers related to COVID-19 could cause indirect damage to testicular function, leading to temporary sub-fertility. 


\section{COVID-19 and male sexual health: the state of} the art

\section{Impact on reproductive hormones}

Several studies have investigated the impact of SARS-CoV-2 on male reproductive hormones (Table 1) [22-24]. Luteinizing hormone and prolactin concentrations appear to be significantly increased in COVID-19-infected men of reproductive age, compared to healthy agematched controls, while follicle-stimulating hormone and estradiol levels seem to be comparable between these groups [22]. Thus, Leydig cells would seem to be more sensitive to viral attack, with possible implications regarding hypogonadism, while Sertoli cells may be more resistant. Schroeder et al. [23] reported that most patients with COVID-19 had low testosterone and dihydrotestosterone levels. Moreover, total testosterone levels have been shown to be inversely proportional to C-reactive protein (CRP) levels in COVID-19-recovered patients [24]. On the basis of these findings, we could speculate that hypogonadism may be related to the severity of COVID-19 infection, most likely due to a body temperature increase and virus-induced autoimmune response, with consequent apoptosis of meiotic germ cells [9,21]. Moreover, since the co-expression of ACE2 and TMPRSS2 occurs only in a small percentage of prostate epithelial cells, prostate infection is unlikely to explain the dysregulation of steroidogenesis mediated by SARS-CoV-2 infection $[13,15,17]$. Furthermore, the sexual hormonal alterations observed in SARS-CoV-2 patients may reflect the global stress response [9,21]. However, to date, very few scientific studies have investigated the presence of SARS-CoV-2 in the seminal fluid, or even within the testicles, as reported below.

\section{Presence in seminal fluid and testis}

A research team focused on this topic analyzed semen samples from a group of 34 men about 1 month after the diagnosis of COVID-19, and reported that viral RNA did not seem to be present [12]. Consistently with this finding, other authors found no presence of viral RNA by RT-PCR in semen or urine samples of patients with laboratory-confirmed SARS-CoV-2 infection, either symptomatic or asymptomatic [25-30]. A possible explanation for this may be the low likelihood of the virus crossing the blood-testis barrier. Indeed, SARS-CoV- 2 appears to be present in the blood in only $1 \%$ of cases [31], which would suggest a low probability of developing viremia.

Conversely, Li et al. [32] enrolled a cohort of 38 SARS-CoV-2-positive patients for semen testing. Among them, 23 had achieved clinical recovery, while 15 were in the acute stage of infection. Six patients (15.8\%) had results positive for SARS-CoV-2, including 4 of the 15 patients (26.7\%) in the acute stage of infection and 2 of the 23 patients (8.7\%) who were recovering. However, the small sample size makes these findings difficult to generalize universally. Furthermore, the single-center study design and the lack of accurate data about the baseline study cohort might have introduced non-negligible statistical bias, thus meaningfully undermining the reliability of the reported findings.

Another further study explored the presence of SARS-CoV-2 RNA in semen and testicular tissue of 12 men suffering from COVID-19 with symptoms of mild severity. In 10 patients with negative pharyngeal swabs, the presence of viral RNA, tested by RT-PCR, was not found in the seminal fluid. Moreover, a patient with a positive swab was negative for the presence of viral RNA in the semen. Only one

Table 1. Studies investigating the impact of SARS-CoV-2 on male reproductive hormones

\begin{tabular}{|c|c|c|c|c|c|c|c|c|}
\hline Study & Study design & $\begin{array}{l}\text { No. of } \\
\text { male } \\
\text { cases }\end{array}$ & Age (yr) & $\begin{array}{l}\text { SARS-CoV-2 } \\
\text { diagnosis }\end{array}$ & $\begin{array}{c}\text { Sex-related } \\
\text { hormones } \\
\text { analyzed }\end{array}$ & $\begin{array}{l}\text { Sex-related } \\
\text { hormone } \\
\text { alterations }\end{array}$ & $\begin{array}{c}\text { Correlation with CRP } \\
\text { and/or biochemical risk } \\
\text { factors }\end{array}$ & $\begin{array}{c}\text { Correlation with } \\
\text { disease severity and/or } \\
\text { poor prognosis }\end{array}$ \\
\hline Ma et al. [22] & $\begin{array}{l}\text { Retrospective } \\
\text { case-control }\end{array}$ & 81 & $38(20-54)$ & Yes & $\begin{array}{r}\text { TT, E2, PG, PRL, } \\
\text { LH, FSH, AMH }\end{array}$ & $\begin{array}{l}\text { LH } \uparrow, \mathrm{PRL} \uparrow, \\
\text { T:LH ratio } \downarrow \\
\text { FSH:LH ratio } \downarrow\end{array}$ & $\begin{array}{l}\text { T:LH ratio negatively } \\
\text { correlated with CRP }\end{array}$ & $\begin{array}{l}\text { T:LH ratio negatively } \\
\text { correlated with } \\
\text { disease severity }\end{array}$ \\
\hline $\begin{array}{l}\text { Schroeder et } \\
\text { al. [23] }\end{array}$ & $\begin{array}{l}\text { Retrospective } \\
\text { single-center } \\
\text { cohort }\end{array}$ & 35 & $62(31-80)$ & Yes & $\begin{array}{l}\text { TT, cFT, DHY-TT, } \\
\text { E2, LH, FSH, } \\
\text { PRL, TSH, T3, T4 }\end{array}$ & $\begin{array}{l}\mathrm{TT} \downarrow, \mathrm{DHY}-\mathrm{TT} \downarrow \\
\mathrm{LH} \uparrow, \mathrm{E} 2 \uparrow\end{array}$ & $\begin{array}{l}\text { TT negatively correlated } \\
\text { with biochemical risk } \\
\text { factors }\end{array}$ & $\begin{array}{l}\text { TT negatively correlated } \\
\text { with disease severity }\end{array}$ \\
\hline $\begin{array}{l}\text { Rastrelli et al. } \\
\text { [24] }\end{array}$ & $\begin{array}{l}\text { Retrospective } \\
\text { single-center } \\
\text { cohort }\end{array}$ & 31 & $\begin{array}{l}21^{\text {b) }} 63(55-66) \\
6^{\text {b) }} 72(33-83) \\
4^{\text {b) }} 74(59-85)\end{array}$ & $\begin{array}{l}\text { Yes } \\
\text { Yes } \\
\text { Yes }\end{array}$ & $\mathrm{TT}, \mathrm{cFT}, \mathrm{LH}, \mathrm{SHBG}$ & $\mathrm{TT} \downarrow, \mathrm{FT} \downarrow, \mathrm{LH} \uparrow$ & $\begin{array}{l}\text { TT negatively correlated } \\
\text { with CRP and bio- } \\
\text { chemical risk factors }\end{array}$ & $\begin{array}{l}\text { TT positively correlated } \\
\text { with poor prognosis }\end{array}$ \\
\hline
\end{tabular}

Values are presented as median (range).

$\uparrow$, increased levels; $\downarrow$, decreased levels; SARS-CoV-2, severe acute respiratory syndrome coronavirus 2; CRP, C-reactive protein; TT, total testosterone; E2, 17- $\beta$-estradiol; PG, progesterone; PRL, prolactin; LH, luteinizing hormone; FSH, follicle-stimulating hormone; AMH, anti-Müllerian hormone; T, testosterone; cFT, calculated free testosterone; DHY-TT, dihydrotestosterone; TSH, thyroid-stimulating hormone; T3, free triiodothyronine; T4, free thyroxine; SHBG, sex hormone binding globulin; RICU, respiratory intensive care unit; IM, internal medicine unit.

${ }^{\text {a)} S A R S-C o V-2 ~ d i a g n o s i s ~ w i t h ~ r e v e r s e-t r a n s c r i p t i o n ~ p o l y m e r a s e ~ c h a i n ~ r e a c t i o n ~ o f ~ n a s a l / p h a r y n g e a l ~ s w a b s ~ a n d ~ c h e s t ~ i m a g i n g ; ~}{ }^{\text {b) }} 21$ : number of patients transferred from RICU to IM, 6: number of patients stable at time of the analysis and maintained in RICU, 4: number of patients worsened their conditions and transferred to ICU. 
patient in the acute phase of disease, who died from COVID-19-related complications, underwent a testicular biopsy, which did not demonstrate the presence of the virus in the tissue [33]. In line with these findings, a recent paper by Flaifel et al. [34] analyzed specimens of the testes and epididymis from a series of 10 SARS-CoV-2positive autopsies. Although the autopsies all showed the presence of SARS-CoV-2 in the respiratory tract, the testicular samples tested by RT-PCR were all negative. However, seven of 10 cases showed significant seminiferous tubular injury, including nuclear fragmentation of spermatocytes, elongation of spermatids, and vacuolization of the Sertoli cells, while 1 case showed an increased mononuclear inflammatory infiltrate (CD8+ dominant) in the interstitial space, compatible with orchitis [34]. In their analysis, the acute morphological changes reported could have been related to oxidative stress and microthrombosis in the testicular vasculature. In addition, the absence of the virus in the testes suggests that direct injury by SARSCoV-2 infection is unlikely [34].

The characteristics of the studies exploring the presence of SARSCoV-2 in semen, urine, and testicular tissue are reported in Table 2 $[12,22,26-30]$. The challenge is to understand whether SARS-CoV-2 can directly infect the testicles, as the main target of the male genital tract, even during the acute phase of the disease. To better understand this issue, it could be useful to have more data from autoptic testicular samples in COVID-19 patients, since we do not know if SARS-CoV-2 is present only in the seminal fluid, binds to spermatozoa, or can even integrate into the cell genome. More recently, Yang et al. [35] examined postmortem testes from 12 COVID-19 patients using RT-PCR. The authors found positive viral detection only in 1 patient with a high viral load. Conversely, concerning morphological changes, the testes from COVID-19 patients exhibited significant seminiferous tubular injuries, reduced Leydig cells, and mild lymphocytic inflammation. Alternatively, hyperthermia, hypoxia, and steroid use could have played a crucial role in testicular damage.

A recent paper by Achua et al. [36] explored the presence of SARSCoV- 2 in the testes of 6 COVID-19-positive autopsies and 3 negative men by hematoxylin and eosin (H\&E) histomorphology and transmission electron microscopy (TEM). They reported that 3 (50\%) SARS-CoV-2 biopsies had normal spermatogenesis, while the other 3 had impaired spermatogenesis on H\&E histomorphology. Moreover, TEM showed SARS-CoV-2 in testis tissue of 1 positive autopsy case and a biopsy obtained from a live patient who was previously diagnosed with SARS-CoV-2 and subsequently seroconverted. In addition, immunofluorescence-stained slides from the positive men demonstrated an association between increased quantitative ACE-2 levels and impairment of spermatogenesis [36]. These findings, especially the inverse association between ACE- 2 receptor levels and spermatogenesis, may suggest that the testes could be a target of
SARS-CoV-2, ultimately providing a possible mechanism of postCOVID-19 infertility. However, that study has several limitations, the main ones being the lack of a detailed analysis of seminal parameters and virus detection by RT-PCR, making these results unreliable.

Although the risk of the presence of SARS-CoV- 2 in semen appears to be low, future studies need to focus on whether complete viral particles can be observed in semen and the possibility of sexual transmission. Furthermore, the embryology community needs to establish the implications of SARS-CoV-2 for assisted reproductive technology and whether the virus can be removed by sperm washing techniques, as with HIV or hepatitis C virus. Moreover, data about how long the virus remains detectable in the seminal fluid, its ability to actively replicate, and its potential for sexual transmission are still lacking. As such, there are still many open questions to be discussed.

\section{Impact on fertility parameters}

Due to the reported high expression of ACE2 in seminiferous tubule cells, spermatogonia, adult Leydig cells, and Sertoli cells of the human testis, and TMPRSS2 expression in prostate epithelial cells, SARS-CoV-2 may be involved in the dysregulation of steroidogenesis $[17,37]$. These findings imply that SARS-CoV-2 infection may have risks for the male reproductive system in terms of impaired spermatogenesis.

In detail, sperm cells express all types of ACEs (1-7) and recent publications reported angiotensin II type 1 receptor (AT1R) and angiotensin II type 2 receptor (AT2R) expression in sperm, suggesting that sperm cells could act as a direct target of SARS-CoV-2 infection $[12,13,16-20,38,39]$. In this scenario, SARS-CoV-2 infection would be expected to impact ACE2 activity, leading to an increase in the availability of angiotensin II in sperm cells, stimulating the acrosome reaction $[13,18,19,37,38]$. This may lead to premature acrosomal exocytosis and sperm senescence [40]. Furthermore, angiotensin II may affect sperm fertilization and motility by stimulating AT1R and AT2R [39].

Although Holtmann et al. [28] in their aforementioned study did not detect SARS-CoV-2 RNA in the semen samples of recovered or acutely infected patients, they found significant impairment of sperm quality (in terms of sperm concentration and motility) in patients with a moderate infection, as compared with men recovered from mild infection and a control group. Similarly, Ma et al. [22,25] reported altered semen quality in four patients (33.3\%), who showed decreased sperm concentration and motility and a higher DNA fragmentation index.

A recent paper from Zhang et al. [41] failed to isolate SARS-CoV-2 in prostatic secretions of patients with active disease; however, they described a significant increase of inflammatory markers such as CRP and interleukin- 6 in these biologic samples. These results, taken together, suggest a potential impact of SARS-CoV-2 on semen param- 


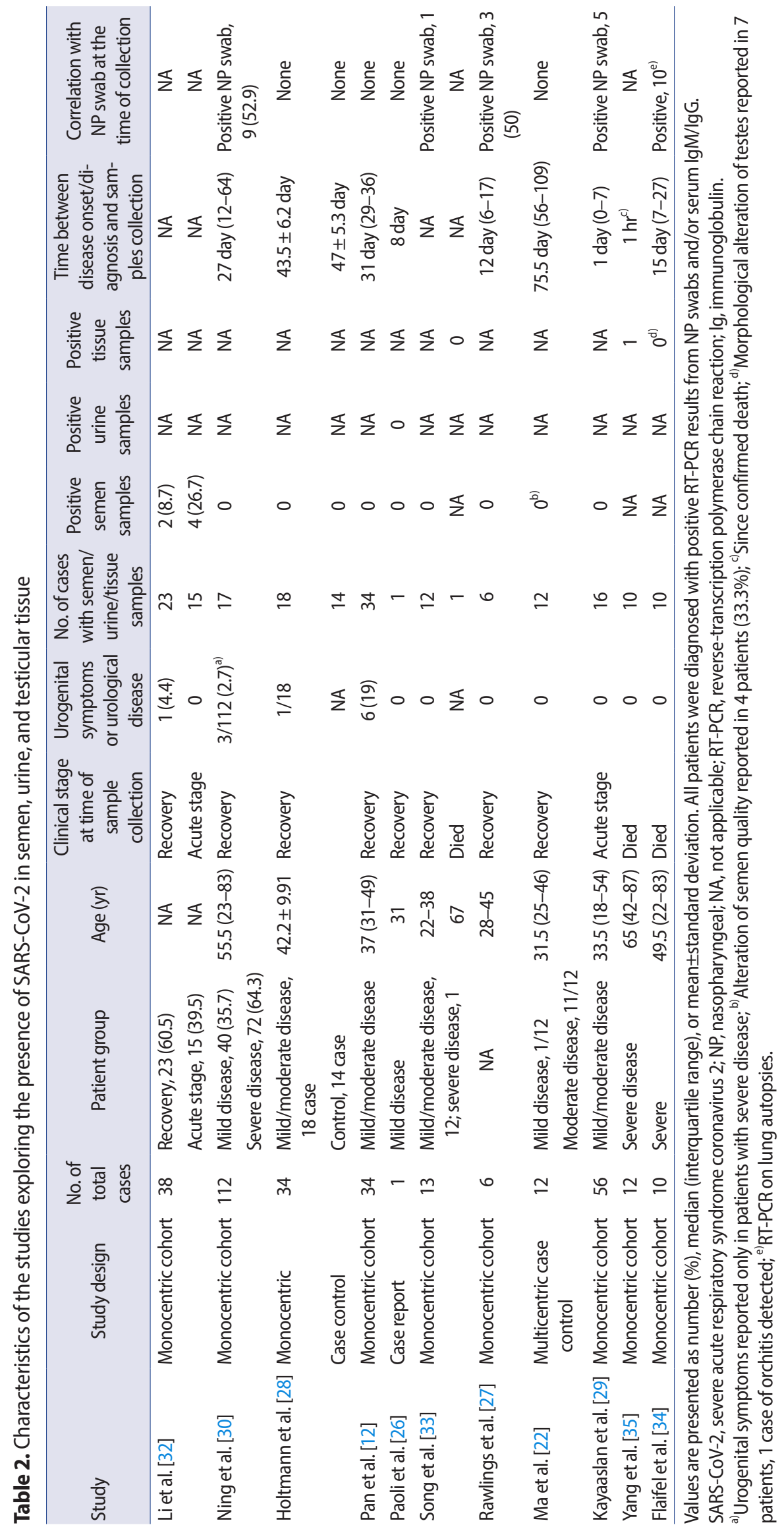


eters and ultimately on male reproductive capability. Therefore, given the widespread SARS-CoV-2 pandemic, direct or indirect fertility decline post-COVID-19 seems to be a possible and significant issue, particularly in the hardest-hit countries $[42,43]$. Given the relevance of these findings, potentially impacting the world's demographics in the near future, we need further and stronger evidence on the real impact of SARS-CoV-2 on male reproductive health.

\section{Conclusion}

To date, there is very limited evidence reporting the presence of SARS-CoV-2 in semen and testicular samples. The studies available do not allow us to draw definitive conclusions or exclude the possibility of viral sexual transmission. Despite the small sample size and several selection biases, the male genital tract represents a potentially susceptible organ to viral infection. However, the real impact of SARS-CoV-2 on male reproductive function still remains to be fully determined.

\section{Conflict of interest}

No potential conflict of interest relevant to this article was reported.

\section{ORCID}

Pierangelo Verrienti
Gianmartin Cito
Fabrizio Di Maida
Riccardo Tellini
Andrea Cocci

https://orcid.org/0000-0002-7596-5961 https://orcid.org/0000-0001-7526-4025 https://orcid.org/0000-0003-1885-4808 https://orcid.org/0000-0003-2189-5352 https://orcid.org/0000-0003-0138-6294

\section{Author contributions}

Conceptualization: PV, GC, AN. Data curation: PV, GC, FDM, RT. Formal analysis: PV, GC, RT. Methodology: PV, GC, FDM, RT. Project administration: $A C, A M, A N$. Visualization: $A C, A M, A N$. Writing-original draft: PV, GC, FDM. Writing-review \& editing: PV, RT, AC, AM, AN.

\section{References}

1. Liu W, Han R, Wu H, Han D. Viral threat to male fertility. Andrologia 2018;50:e13140.

2. Wang D, Hu B, Hu C, Zhu F, Liu X, Zhang J, et al. Clinical characteristics of 138 hospitalized patients with 2019 novel coronavirus-infected pneumonia in Wuhan, China. JAMA 2020;323:1061-9.

3. Wong SF, Chow KM, Leung TN, Ng WF, Ng TK, Shek CC, et al. Preg- nancy and perinatal outcomes of women with severe acute respiratory syndrome. Am J Obstet Gynecol 2004;191:292-7.

4. Alfaraj SH, Al-Tawfiq JA, Memish ZA. Middle east respiratory syndrome coronavirus (MERS-CoV) infection during pregnancy: report of two cases \& review of the literature. J Microbiol Immunol Infect 2019;52:501-3.

5. Duggal NK, Ritter JM, Pestorius SE, Zaki SR, Davis BS, Chang GJ, et al. Frequent Zika virus sexual transmission and prolonged viral RNA shedding in an immunodeficient mouse model. Cell Rep 2017;18:1751-60.

6. Deen GF, Broutet N, Xu W, Knust B, Sesay FR, McDonald SL, et al. Ebola RNA persistence in semen of ebola virus disease survivors: final report. N Engl J Med 2017;377:1428-37.

7. Pike JF, Polley EL, Pritchett DY, Lal A, Wynia BA, Roudebush WE, et al. Comparative analysis of viral infection outcomes in human seminal fluid from prior viral epidemics and Sars-CoV-2 may offer trends for viral sexual transmissibility and long-term reproductive health implications. Reprod Health 2021;18:123.

8. Mansuy JM, Suberbielle E, Chapuy-Regaud S, Mengelle C, Bujan L, Marchou B, et al. Zika virus in semen and spermatozoa. Lancet Infect Dis 2016;16:1106-7.

9. Dejucq N, Jegou B. Viruses in the mammalian male genital tract and their effects on the reproductive system. Microbiol Mol Biol Rev 2001;65:208-31.

10. Tur-Kaspa I, Tur-Kaspa T, Hildebrand G, Cohen D. COVID-19 may affect male fertility but is not sexually transmitted: a systematic review. F S Rev 2021;2:140-9.

11. Xu J, Qi L, Chi X, Yang J, Wei X, Gong E, et al. Orchitis: a complication of severe acute respiratory syndrome (SARS). Biol Reprod 2006;74:410-6.

12. Pan F, Xiao X, Guo J, Song Y, Li H, Patel DP, et al. No evidence of severe acute respiratory syndrome-coronavirus 2 in semen of males recovering from coronavirus disease 2019. Fertil Steril 2020;113: 1135-9.

13. Verma S, Saksena S, Sadri-Ardekani H. ACE2 receptor expression in testes: implications in coronavirus disease 2019 pathogenesis. Biol Reprod 2020;103:449-51.

14. Stanley KE, Thomas E, Leaver M, Wells D. Coronavirus disease-19 and fertility: viral host entry protein expression in male and female reproductive tissues. Fertil Steril 2020;114:33-43.

15. Song H, Seddighzadeh B, Cooperberg MR, Huang FW. Expression of ACE2, the SARS-CoV-2 receptor, and TMPRSS2 in prostate epithelial cells. Eur Urol 2020;78:296-8.

16. Li W, Moore MJ, Vasilieva N, Sui J, Wong SK, Berne MA, et al. Angiotensin-converting enzyme 2 is a functional receptor for the SARS coronavirus. Nature 2003;426:450-4.

17. Wang Z, Xu X. scRNA-seq profiling of human testes reveals the 
presence of the ACE2 receptor, a target for SARS-CoV-2 infection in spermatogonia, Leydig and Sertoli cells. Cells 2020;9:920.

18. Shastri A, Wheat J, Agrawal S, Chaterjee N, Pradhan K, Goldfinger $\mathrm{M}$, et al. Delayed clearance of SARS-CoV2 in male compared to female patients: high ACE2 expression in testes suggests possible existence of gender-specific viral reservoirs. medRxiv [Preprint]. 2020 [cited 2022 Jan 10]. Available from: https://doi.org/10.1101/ 2020.04.16.20060566.

19. Vishvkarma R, Rajender S. Could SARS-CoV-2 affect male fertility? Andrologia 2020;52:e13712.

20. Zou X, Chen K, Zou J, Han P, Hao J, Han Z. Single-cell RNA-seq data analysis on the receptor ACE2 expression reveals the potential risk of different human organs vulnerable to 2019-nCoV infection. Front Med 2020;14:185-92.

21. Xu J, Xu Z, Jiang Y, Qian X, Huang Y. Cryptorchidism induces mouse testicular germ cell apoptosis and changes in bcl-2 and bax protein expression. J Environ Pathol Toxicol Oncol 2000;19:25-33.

22. Ma L, Xie W, Li D, Shi L, Mao Y, Xiong Y, et al. Effect of SARS-CoV-2 infection upon male gonadal function: a single center-based study. medRxiv [Preprint]. 2020 [cited 2022 Jan 10]. Available from: http://medrxiv.org/content/early/2020/03/30/2020.03. 21.20037267.

23. Schroeder M, Schaumburg B, Mueller Z, Parplys A, Jarczak D, Roedl K, et al. High estradiol and low testosterone levels are associated with critical illness in male but not in female COVID-19 patients: a retrospective cohort study. Emerg Microbes Infect 2021;10:1807-18.

24. Rastrelli G, Di Stasi V, Inglese F, Beccaria M, Garuti M, Di Costanzo D, et al. Low testosterone levels predict clinical adverse outcomes in SARS-CoV-2 pneumonia patients. Andrology 2021;9:88-98.

25. Ma L, Xie W, Li D, Shi L, Ye G, Mao Y, et al. Evaluation of sex-related hormones and semen characteristics in reproductive-aged male COVID-19 patients. J Med Virol 2021;93:456-62.

26. Paoli D, Pallotti F, Colangelo S, Basilico F, Mazzuti L, Turriziani O, et al. Study of SARS-CoV-2 in semen and urine samples of a volunteer with positive naso-pharyngeal swab. J Endocrinol Invest 2020;43:1819-22.

27. Rawlings SA, Ignacio C, Porrachia M, Du P, Smith DM, Chaillon A. No evidence of SARS-CoV-2 seminal shedding despite SARSCoV-2 persistence in the upper respiratory tract. Open Forum Infect Dis 2020;7:ofaa325.

28. Holtmann N, Edimiris P, Andree M, Doehmen C, Baston-Buest D, Adams $\mathrm{O}$, et al. Assessment of SARS-CoV-2 in human semen-a cohort study. Fertil Steril 2020;114:233-8.

29. Kayaaslan B, Korukluoglu G, Hasanoglu I, Kalem AK, Eser F, Akinci $\mathrm{E}$, et al. Investigation of SARS-CoV-2 in semen of patients in the acute stage of COVID-19 infection. Urol Int 2020;104:678-83.
30. Ning J, Li W, Ruan Y, Xia Y, Wu X, Hu K, et al. Effects of 2019 novel coronavirus on male reproductive system: a retrospective study. Preprints [Preprint]. 2020 [cited 2022 Jan 10]. Available from: https://doi.org/10.20944/ preprints202004.0280.v1.

31. Cui P, Chen Z, Wang T, Dai J, Zhang J, Ding T, et al. Clinical features and sexual transmission potential of SARS-CoV-2 infected female patients: a descriptive study in Wuhan, China. medRxiv [Preprint]. 2020 [cited 2022 Jan 10]. Available from: https://doi.org/10.1101/ 2020.02.26.20028225.

32. Li D, Jin M, Bao P, Zhao W, Zhang S. Clinical characteristics and results of semen tests among men with coronavirus disease 2019 JAMA Netw Open 2020;3:e208292.

33. Song C, Wang Y, Li W, Hu B, Chen G, Xia P, et al. Detection of 2019 novel coronavirus in semen and testicular biopsy specimen of COVID-19 patients. medRxiv [Preprint]. 2020 [cited 2022 Jan 10]. Available from: https://doi.org/10.1101/2020.03.31.20042333.

34. Flaifel A, Guzzetta M, Occidental M, Najari BB, Melamed J, Thomas KM, et al. Testicular changes associated with severe acute respiratory syndrome coronavirus 2 (SARS-CoV-2). Arch Pathol Lab Med 2021;145:8-9.

35. Yang M, Chen S, Huang B, Zhong JM, Su H, Chen YJ, et al. Pathological findings in the testes of COVID-19 patients: clinical implications. Eur Urol Focus 2020;6:1124-9.

36. Achua JK, Chu KY, Ibrahim E, Khodamoradi K, Delma KS, lakymenko OA, et al. Histopathology and ultrastructural findings of fatal COVID-19 infections on testis. World J Mens Health 2021;39:65-74.

37. Shang J, Wan Y, Luo C, Ye G, Geng Q, Auerbach A, et al. Cell entry mechanisms of SARS-CoV-2. Proc Natl Acad Sci U S A 2020;117: 11727-34.

38. Al-Qahtani AA. Severe acute respiratory syndrome coronavirus 2 (SARS-CoV-2): emergence, history, basic and clinical aspects. Saudi J Biol Sci 2020;27:2531-8.

39. Aitken RJ. COVID-19 and human spermatozoa: potential risks for infertility and sexual transmission? Andrology 2021;9:48-52.

40. Kohn FM, Muller C, Drescher D, Neukamm C, el Mulla KF, Henkel R, et al. Effect of angiotensin converting enzyme (ACE) and angiotensins on human sperm functions. Andrologia 1998;30:207-15.

41. Zhang S, Wang X, Zhang H, Xu A, Fei G, Jiang X, et al. The absence of coronavirus in expressed prostatic secretion in COVID-19 patients in Wuhan city. Reprod Toxicol 2020;96:90-4.

42. Aassve A, Cavalli N, Mencarini L, Plach S, Livi Bacci M. The COVID-19 pandemic and human fertility. Science 2020;369:370-1.

43. Cocci A, Giunti D, Tonioni C, Cacciamani G, Tellini R, Polloni G, et al. Love at the time of the Covid-19 pandemic: preliminary results of an online survey conducted during the quarantine in Italy. Int J Impot Res 2020;32:556-7. 